\title{
Inappropriate ED visits: patient responsibility or an attribution bias?
}

\author{
Krisda Chaiyachati, Shreya Kangovi
}

Department of Medicine, Division of General Internal Medicine, University of Pennsylvania, Philadelphia, Pennsylvania, USA

\section{Correspondence to} Dr Krisda Chaiyachati, University of Pennsylvania, Philadelphia, PA 19104, USA;

kchai@pennmedicine.upenn.edu

Accepted 24 October 2019 Published Online First 4 November 2019

\section{Sinked}

- http://dx.doi.org/10.1136/ bmjqs-2019-009396

\section{Check for updates}

(c) Author(s) (or their employer(s)) 2020. No commercial re-use. See rights and permissions. Published by BMJ.

To cite: Chaiyachati K, Kangovi S. BMJ Qual Saf 2020;29:441-442.
The study by Naouri et al in this issue of BMJ Quality and Safety describes an ambitious, 24-hour cross-sectional physician survey and chart review of all the emergency departments (ED) in France to characterise the 'inappropriateness' of ED visits. ${ }^{1}$ The determination of inappropriateness for any given visit was based on (A) physician opinion, (B) physician determination of ambulatory care sensitivity, or (C) resource utilisation. Based on these measures, the authors concluded that between $13 \%$ and $27 \%$ of $\mathrm{ED}$ visits were inappropriate. Further, patients with supplemental public insurance (a proxy for the socioeconomic disadvantaged in France) were 15\%-33\% more likely to use the ED inappropriately.

Naouri's study is part of a growing body of literature that characterises ED use as inappropriate, avoidable, ambulatory care sensitive or preventable. ${ }^{2}{ }^{3}$ While there is precedent and potential merit in classifying healthcare services based on their value, ${ }^{4}$ this trend raises some concerns-as the authors rightly conclude-when describing the use of EDs by disadvantaged populations.

Determining the patient's ED visit as inappropriate, without consideration of broader contextual factors, is an example of attribution bias: the tendency for people to overemphasise individual and personality-based explanations for behaviours while underemphasising situational explanations. ${ }^{5}$ We may blame patients for visiting the ED inappropriately, when in reality, healthcare systems are often designed to funnel patients towards the ED. A historical perspective may be useful in justifying this assertion.

For generations, there has been a tremendous imbalance in the revenue generated by hospital versus outpatient services. On an aggregate level, hospital stays in the USA generated US $\$ 27$ billion more than outpatient visits in $2017 .^{6}$ Similar disparities in revenue generation between inpatient and outpatient care exists across the globe irrespective of a country's healthcare financing structure. ${ }^{7}$

This lopsided revenue has incentivised healthcare systems to funnel patients into hospitals instead of preventing illness in community or practice-based settings. Primary care practices and communitybased services such as home care have fewer resources to manage the growing complexity of ageing, chronically ill and comorbid populations. ${ }^{8}$ High-quality primary care is even more elusive for patients with socioeconomic risk. ${ }^{9} \mathrm{Naou}-$ ri's study supports these conclusions: patients visiting EDs often did so because they could not find an available general practitioner or were referred to the ED by their general practitioner.

By contrast, EDs-gateways to the revenue-generating hospital-are convenient one-stop shops replete with resources. So, it should not surprise us when patients-especially those with social risk-visit the ED. This observation is a reflection of the system that we have built and a side effect is ED overcrowding.

So, where do we go from here? If we approached the problem of excessive hospital use solely as the consequence of patient choice, we might continue our current tiring paths. We could impose cost sharing on patients for 'inappropriate' ED visits. These strategies have reduced ED use ${ }^{10}$ but may result in unintended health and financial harms to patients by creating financial barriers to care, particularly among the highest risk individuals. Alternatively, we might continue designing gatekeeper strategies such as nurse access lines employed by insurance companies. These approaches raise the spectre for discrimination and inequity, as minorities and disadvantaged patients commonly use the ED and are the most likely to be diverted. Indeed, this concern is significant enough that in the USA, patients have long been protected under the US Emergency 
Medical Treatment and Active Labor Act, preventing EDs from turning patients away for any reason.

We recommend three key considerations for healthcare provider organisations as they try to address overcrowding in the ED.

First, hospitals and administrators should recognise the potential for implicit or explicit bias when determining the inappropriateness of ED visits based on narrow clinician perspectives. If we instead assume that patients are usually the best judge of when and where to seek care, we might reinterpret the following finding from Naouri's study: $25 \%$ of the time, ED physicians deemed patient visits inappropriate. While Naouri et al concluded that inappropriate ED visits were higher among socially disadvantaged patients, socially disadvantaged patients might have been victims of clinicians' biased judgements.

Second, a more user-centric approach would develop alternative paths of care that mirror the convenience and timeliness of EDs. Urgent care centres, retail health clinics and telemedicine have become exponentially popular in the USA because of consumer demands. To compete, traditional healthcare provider organisations have enhanced access to outpatient practices with extended after-hours care. However, with some exceptions, the expanded time availabilities have not been matched by expanded clinical infrastructure (ie, on-site laboratory testing and imaging). So, patients often sense that even when they get timely appointments, practices are ill equipped to help them. ${ }^{8}$ Ultimately, efforts to grow the clinical capacity of practices may have constraints. Provider shortages are a global challenge and working weekends and late evenings are unlikely to mitigate the growing wave of burnout and depression among providers. And efforts to outfit practices with more clinical infrastructure may reach a point of diminishing financial returns. Centralising these resources in the ED or hospitals may in the end be the most efficient approach.

Third, if our goal is truly to reduce ED use, then it makes sense to invest in interventions that address the underlying socioeconomic issues-hunger, joblessness, trauma-that often drive acute illness and ED utilisation in the first place. There is a growing literature that suggests that health system-based socioeconomic interventions ${ }^{11}{ }^{12}$-including support from community health workers ${ }^{13-15}$ — can decrease hospital use while improving health and quality.

The problem of ED utilisation in France and the USA is probably less the result of inappropriate patient decisionmaking, and more the result of healthcare's inability to adapt to the needs and preferences of patients. In the USA, changes may be on the horizon. Since the passage of the 2010 Affordable Care Act, payment has shifted towards value-based payments for healthcare services, including capitated or bundled payment structures. Value flips the incentives that exist in a fee-for-service environment: instead of doing more at greater cost, hospitals make money by doing less in higher cost settings. And so, with a changing incentive structure and studies like the one by Naouri et al, healthcare provider organisation should shift towards identifying better delivery approaches that meet patient needs in more cost-effective settings rather than blaming patients for accessing the care they need.

Funding The authors have not declared a specific grant for this research from any funding agency in the public, commercial or not-for-profit sectors.

Competing interests None declared.

Patient consent for publication Not required.

Provenance and peer review Commissioned; internally peer reviewed.

\section{REFERENCES}

1 Naouri D, Ranchon G, Vuagnat A, et al. Is inappropriate emergency department use still an appropriate concept? findings from a cross-sectional national study in France. BMJ Qual Saf 2020;29:449-64.

2 Pines JM, Hilton JA, Weber EJ, et al. International perspectives on emergency department crowding. Acad Emerg Med 2011;18:1358-70.

3 Dowd B, Karmarker M, Swenson T, et al. Emergency department utilization as a measure of physician performance. Am J Med Qual 2014;29:135-43.

4 Goldbach P. The choosing wisely campaign. Health Aff 2018;37:335.

5 Fiske ST, Taylor SE. Social cognition: from brains to culture. Sage, 2013.

6 American Hospital Association. Trendwatch Chartbook 2018: trends affecting hospitals and health systems, 2018. Available: https://www.aha.org/system/files/2018-07/2018-aha-chartbook. pdf [Accessed 12 Jul 2019].

7 World Health Organization. Health service delivery costs, 2011. Available: https://www.who.int/choice/cost-effectiveness/ inputs/health_service/en/ [Accessed 12 Jul 2019].

8 Kangovi S, Kellom K, Sha C, et al. Perceptions of high-risk patients and their providers on the patient-centered medical home. J Ambul Care Manage 2015;38:134-43.

9 Kangovi S, Barg FK, Carter T, et al. Understanding why patients of low socioeconomic status prefer hospitals over ambulatory care. Health Aff 2013;32:1196-203.

10 Petrou P, Ingleby D. Co-payments for emergency department visits: a quasi-experimental study. Public Health 2019;169:50-8.

11 Gottlieb LM, Wing H, Adler NE. A Systematic Review of Interventions on Patients' Social and Economic Needs. Am J Prev Med 2017;53:719-29.

12 Taylor LA, Tan AX, Coyle CE, et al. Leveraging the social determinants of health: what works? PLoS One 2016;11:e0160217.

13 Kangovi S, Mitra N, Grande D, et al. Patient-Centered community health worker intervention to improve Posthospital outcomes. JAMA Intern Med 2014;174:535-43.

14 Kangovi S, Mitra N, Grande D, et al. Community health worker support for disadvantaged patients with multiple chronic diseases: a randomized clinical trial. Am J Public Health 2017;107:1660-7.

15 Kangovi S, Mitra N, Norton L, et al. Effect of community health worker support on clinical outcomes of low-income patients across primary care facilities. JAMA Intern Med 2018;178:1635-43. 